\title{
Article \\ Hybrid Metal-Organic Framework-Cellulose Materials Retaining High Porosity: ZIF-8@Cellulose Nanofibrils
}

\author{
Johannes Thunberg ${ }^{1,2,3}{ }^{\oplus}$, Savannah C. Zacharias ${ }^{4,5} \oplus^{\circ}$, Merima Hasani ${ }^{1}$, Olayinka. A. Oyetunji ${ }^{6}$, \\ Francoise M. Amombo Noa ${ }^{1} \mathbb{D}$, Gunnar Westman ${ }^{1,2}{ }^{\mathbb{D}}$ and Lars Öhrström ${ }^{1, *}$ \\ 1 Department of Chemistry and Chemical Engineering, Chalmers University of Technology, \\ 41296 Gothenburg, Sweden; johannes.thunberg@gmail.com (J.T.); merima.hasani@chalmers.se (M.H.); \\ mystere@chalmers.se (F.M.A.N.); westman@chalmers.se (G.W.) \\ 2 Wallenberg Wood Science Center, Chalmers University of Technology, 41296 Gothenburg, Sweden \\ 3 Borealis AB, Munkerödsvägen 11, 44432 Stenungsund, Sweden \\ 4 Department of Chemistry, University of Cape Town, Rondebosch 7700, South Africa; \\ savannah.zacharias@gu.se \\ 5 Department of Chemistry and Molecular Biology, University of Gothenburg, Kemivägen 10, \\ 41296 Gothenburg, Sweden \\ 6 Department of Chemistry, University of Botswana, Private Bag UB 00704, Gaborone, Botswana; \\ oyetunji@ub.ac.bw \\ * Correspondence: ohrstrom@chalmers.se; Tel.: +46-31-772-2871
}

check for updates

Citation: Thunberg, J.; Zacharias, S.C.; Hasani, M.; Oyetunji, O.A.; Noa, F.M.A.; Westman, G.; Öhrström, L. Hybrid Metal-Organic

Framework-Cellulose Materials Retaining High Porosity: ZIF-8@Cellulose Nanofibrils. Inorganics 2021, 9, 84. https:// doi.org/10.3390/inorganics9110084

Academic Editor: Francis Verpoort

Received: 29 October 2021

Accepted: 17 November 2021

Published: 20 November 2021

Publisher's Note: MDPI stays neutral with regard to jurisdictional claims in published maps and institutional affiliations.

Copyright: (c) 2021 by the authors. Licensee MDPI, Basel, Switzerland. This article is an open access article distributed under the terms and conditions of the Creative Commons Attribution (CC BY) license (https:/ / creativecommons.org/licenses/by/ $4.0 /)$.

\begin{abstract}
Metal-organic frameworks have attracted a great deal of attention for future applications in numerous areas, including gas adsorption. However, in order for them to reach their full potential a substrate to provide an anchor may be needed. Ideally, this substrate should be environmentally friendly and renewable. Cellulose nanofibrils show potential in this area. Here we present a hybrid material created from the self-assembly of zeolitic imidazolate framework (ZIF-8) nanocrystals on cellulose nanofibrils (CNF) in aqueous medium. The CNF/ZIF-8 was freeze dried and formed free standing materials suitable for gas adsorption. A BET area of $1014 \mathrm{~m}^{2} \mathrm{~g}^{-1}$ was achieved for the CNF/ZIF-8 hybrid materials ZIF-8@cellulose which is comparable with reported values for free standing ZIF-8 materials, $1600 \mathrm{~m}^{2} \mathrm{~g}^{-1}$, considering the dilution with cellulose, and a considerable enhancement compared to CNF on its own, $32 \mathrm{~m}^{2} \mathrm{~g}^{-1}$.
\end{abstract}

Keywords: nanocellulose; metal-organic framework; ZIF-8; hybrid materials; BET surface area; green chemistry

\section{Introduction-Cellulose and Metal-Organic Frameworks, MOFs}

Cellulose Nanofibrils (CNF), also referred to as nanofibrillar cellulose or microfibrillated cellulose [1], can be extracted from cellulosic pulp by mechanical liberation of nano-sized cellulose fibrils [2]. The cellulosic pulp can be oxidized before mechanical treatment in order to decrease the mechanical work needed for fibril liberation [3]. Compared to pulp fibers, CNF materials are advantageous for the preparation of hybrid materials engineered on the nano and molecular scales since the fibrils are on a nanometer scale eliminating defects associated with the hierarchical structure of wood fibers. CNF-based materials also have high strength and stiffness and are lightweight [3]. Both unmodified CNF and surface modified cellulose fibrils have been used as filtering membranes [4-6].

More advanced filtering membranes can be envisaged if the filter incorporates materials that can selectively capture molecules or ions, and good candidates might be some of the new microporous materials that have seen light the last 20 years [7]. Foremost among these are the metal-organic frameworks (MOFs) [8,9]. For example, recently, normal filter paper was carboxymethylated and the MOFs ZIF-8 and ZIF-67 (based on 2-imidazolate and $\mathrm{Zn}^{2+}$ or $\mathrm{Co}^{2+}$ respectively) were grown directly on the fibers [10]. Materials engineered on a more molecular level may be obtained if MOFs are combined with the aforementioned 
Cellulose Nanofibrils (CNF) instead of bulk cellulose fibers. Reviews covering MOFs on a variety of biopolymers, including cellulose, have recently been published [11,12].

Additional uses for these MOF-cellulose hybrid materials may be possible, given that MOFs now are thought of not only for catalysis, gas storage, drug delivery, and gas purification, but also for encapsulating viruses and cells [13] or specific applications such as food quality control [14] and the destruction of chemical warfare agents [15] among others [8]. Supercapacitor and fire-retardant properties have been reported, [16,17] as well as ZIF-8 on a CNF composite membrane for highly selective removal of cationic dye [18]. Recently, the detoxification of chemical warfare agent simulants [19] and selective capture of $\mathrm{U}(\mathrm{VI})$ [20] were also reported.

One of the first examples of combining MOFs with cellulose was by Kaskel in 2009 who grew HKUST-1 directly on pulp fibers [21]. Other early examples used mainly cotton derived fibers, quite different from wood derived cellulose, [22-24] and an example using paper [25]. In our earlier work we used HKUST-1 layer-by-layer grown on electrospun cellulose fibers from soft wood [26]. In this work, we take a slightly different approach with the imidazolate-based MOF ZIF-8 and a green synthesis method.

ZIF-8 is a suitable MOF to combine with cellulose, as it is chemically and thermally stable and can been synthesized in aqueous medium [27-29]. Recently MOF layers such as ZIF- $\mathrm{CO}_{3}-1$ were obtained on CNF in an aqueous preparation with the help of the surfactant polyvinylpyrrolidone (PVP) [30], and also dextran-ZIF-8 composites have been prepared [31].

Moreover, there are several examples of composite materials comprised of ZIF-8 and cellulose being used for potential application such as separation of gases [32-34], and water treatment [35-38].

The use of water as synthesis medium for MOFs open up the possibility to easily synthesize MOFs on cellulose and especially on CNF, since it is extracted as water-based gel. In addition, a water-based synthesis has the potential to be easy and inexpensive to scale up, and environmentally friendly.

However, a challenge in all post-processing or hybrid material manufacturing of MOFcontaining materials is to maintain the high porosity and large surface area of the MOF. Therefore, while crystals of ZIF-8 has a surface area $\mathrm{S}_{\mathrm{BET}}$ of $1600 \mathrm{~m}^{2} \mathrm{~g}^{-1}$, [28] recent work on ZIF-8@cellulose using an aqueous preparation method and cellulose fibers from bleached softwood kraft pulp gave a surface area of $621 \mathrm{~m}^{2} \mathrm{~g}^{-1}$ [39]. The dimethylformamide (dmf)-based synthesis of ZIF-8@cellulose with CNF indicated a S SET of $476 \mathrm{~m}^{2} \mathrm{~g}^{-1}$ [36]. Likewise surface areas of $299.1,348.5$, and $509.9 \mathrm{~m}^{2} / \mathrm{g}$ were reported for ZIF-8 on cellulose nanocrystals [40]. In this work we present the synthesis in aqueous medium of a free standing ZIF-8/CNF material using 2,2,6,6-tetramethylpiperidin-1-oxyl (TEMPO) oxidized CNF from softwood kraft pulp which significantly improve the $S_{\text {BET }}$ of the hybrid material to $1014 \mathrm{~m}^{2} \mathrm{~g}^{-1}$ [41]. We note ref [18] reports a similar material obtained with a multi-step process compared to our one pot procedure and without reporting any gas sorption data.

\section{Results and Discussion}

ZIF-8 was synthesized by addition of $\mathrm{Zn}\left(\mathrm{NO}_{3}\right)_{2}$ to aqueous solutions of $\mathrm{CNF} / 2$ methylimidazole which caused CNF and ZIF-8 to precipitate (Figure 1).

Two distinct phases separated, a clear upper phase and an opaque gel-like lower phase (Figure 2). ZIF-8 synthesis without CNF yielded only precipitation of solid material and no distinct phases. This co-precipitation indicates adhesion between the ZIF- 8 crystallites and $\mathrm{CNF}$, since there was a clear upper phase. After removal of excess 2-methylimidazole, ZIF-8/CNF hybrid materials were created by freeze drying. The ZIF-8/CNF hybrid materials were free standing, but more brittle than plain freeze dried CNF. The amount of 2methylimidazole and $\mathrm{Zn}\left(\mathrm{NO}_{3}\right)_{2}$ in each synthesis were fixed, due to the high concentration ratio of [2-methylimidazole]/[ $\left.\mathrm{Zn}^{2+}\right]$ necessary for the formation of ZIF-8 in water [27]. Two different loadings of CNF were used in order to receive CNF materials with different loading of ZIF-8. 
A

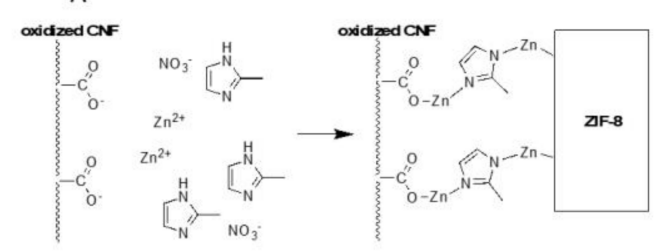

B

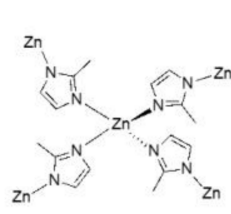

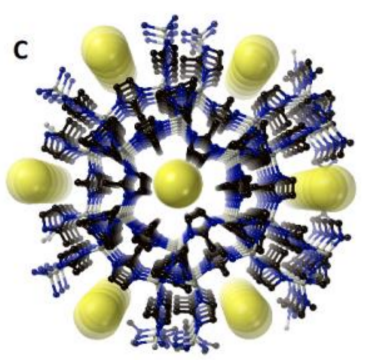

Figure 1. (A): Synthesis of ZIF-8 on oxidized CNF in water. (B): The tetrahedral coordination of Zn in ZIF-8. (C): Structural representation of ZIF-8 (Cambridge Structural Database code FAWCEN [42]) with the cavities represented by yellow spheres and hydrogen atoms omitted for clarity.

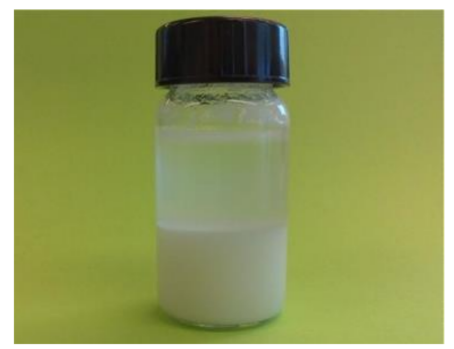

Figure 2. A photo of phase separated CNF-ZIF-8 after synthesis.

The presence of ZIF-8 was confirmed with powder X-ray diffraction (PXRD) and FT-IR. The PXRD patterns of CNF and the ZIF-8@cellulose nanofibril materials are shown in Figure 3, together with a ZIF-8 reference pattern (CSD-[FAWCEN]) [42] generated by the software Mercury 3.3. The high similarity of these patterns proves the formation of ZIF-8 crystallites of sodalite topology in the CNF/ZIF-8 hybrid materials.

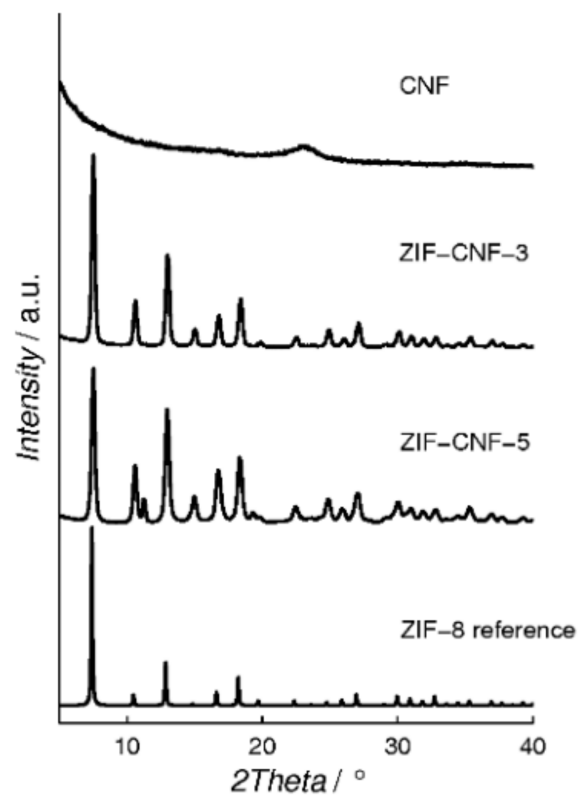

Figure 3. PXRD patterns of CNF, ZIF-CNF-5 and ZIF-CNF-3 and a calculated ZIF-8 reference pattern for comparison.

In Figure 4, characteristic vibration bands at 695, 758, 995, 1148, 1180, $1310 \mathrm{~cm}^{-1}$ are visible for the ZIF-8/CNF hybrid materials, these are consistent with published FT-IR data of ZIF-8 [27,43]. The cellulose polysaccharide vibration bands at 1034, 1056, 1110 and $1160 \mathrm{~cm}^{-1}$ are clearly distinguishable for the CNF Sample. Additionally, a vibration 
band at $1600 \mathrm{~cm}^{-1}$ in the CNF sample corresponding to a $\mathrm{C}=\mathrm{O}$ stretch [44] confirming the oxidized state of CNF. As anticipated, based on the high loading of ZIF-8, in both the FT-IR and XRD analysis the ZIF-8 contributions to the respective spectra dominate in these hybrid materials.

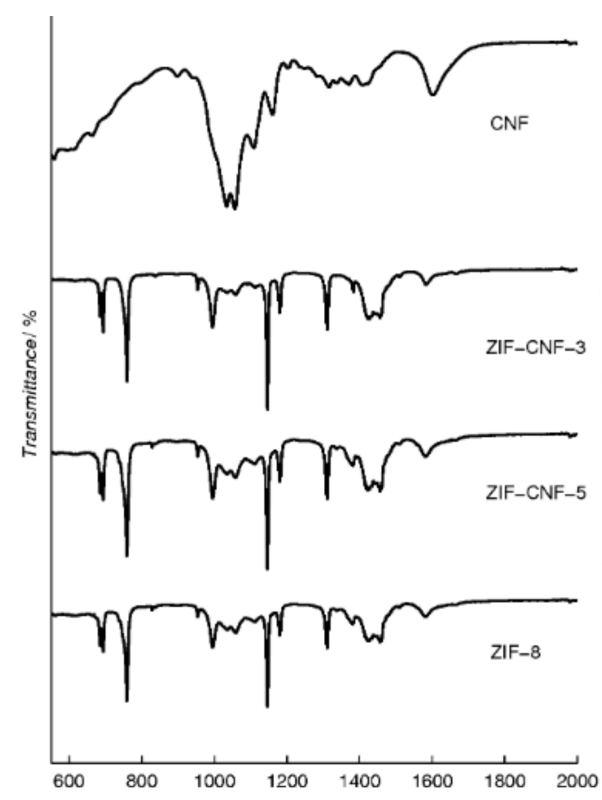

Figure 4. FT-IR spectra of CNF, ZIF-CNF-5 ZIF-CNF-3 and ZIF-8.

Figure 5 illustrates the free standing freeze dried CNF/ZIF-8 hybrid materials and SEM images at $1 \mathrm{k}$ and $25 \mathrm{k}$ magnification of the CNF/ZIF- 8 hybrid material surface. The surface seems to be covered by nano-sized ZIF- 8 crystallites. In Figure $5 \mathrm{~d}$ a fractured surface of CNF/ZIF-8 hybrid material shows what seems to be cellulose fibrillar structures together with nano-sized ZIF-8 crystallites. The fibrils seem to be evenly distributed throughout the material and can act as reinforcement and hold the ZIF-8 particles together.
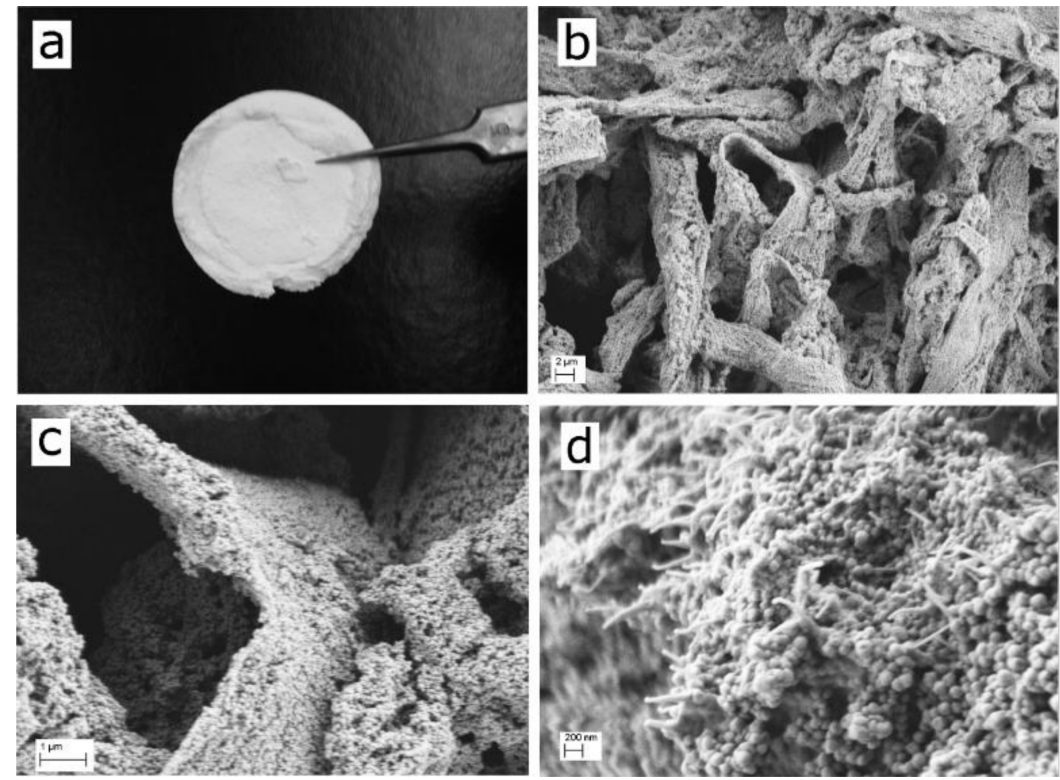

Figure 5. Digital photograph of (a) CNF-ZIF-8, SEM image of (b) CNF-ZIF-8 at 1k magnification, SEM image of (c) CNF-ZIF-8 at 25k magnification, SEM image (d) of fractured surface of CNF-ZIF-8 at $42 \mathrm{k}$ magnification. 
To verify the porosity of these new hybrid materials gas sorption isotherms were determined with $\mathrm{N}_{2}$ gas at $77 \mathrm{~K}$. The obtained results demonstrate a dramatic increase in surface area compared to unmodified freeze dried CNF, and a significant increase compared to other ZIF-8@cellulose materials [36,39]. Table 1 shows the loading of ZIF-8 and the BET surface area for the synthesized CNF-ZIF hybrid materials and plain freeze dried CNF.

Table 1. Summary of results of the characterization of the CNF/ZIF-8 hybrid materials.

\begin{tabular}{cccc}
\hline Material Sample & CNF $^{\mathbf{a}}$ [g] & ZIF-8 Content $^{\mathbf{b}}$ [wt $\%$ ] & BET Surface Area $\mathbf{m}^{\mathbf{2}} \mathbf{~ g}^{-\mathbf{1}}$ ] \\
\hline ZIF-CNF-3 & 3 & 79.7 & 1014 \\
ZIF-CNF-5 & 5 & 68.8 & 528 \\
CNF & - & - & 32 \\
\hline
\end{tabular}

a Amount of CNF used in each sample. ${ }^{\mathrm{b}}$ Estimated from $\mathrm{Zn}$ content.

$\mathrm{N}_{2}$ adsorption and desorption data (Figure 6) show that $\mathrm{N}_{2}$ adsorption dramatically increases for the CNF-ZIF hybrid materials compared to unmodified freeze dried CNF. The BET surface area of plain freeze dried CNF was $32 \mathrm{~m}^{2} \mathrm{~g}^{-1}$, while the surface area of CNF-ZIF material with the highest loading of ZIF-8 was $1014 \mathrm{~m}^{2} \mathrm{~g}^{-1}$ (Table 1). Tanaka et al. reported a BET surface area of pure aqueous synthesized ZIF-8 of $1600 \mathrm{~m}^{2} \mathrm{~g}^{-1}$, which means that a higher BET area for a material with $79.7 \%$ ZIF-8 loading is possible. MOF materials have been synthesized on other cellulosic materials. Küsgens et al. reached a loading of $19.9 \%$ and a BET surface area of $314 \mathrm{~m}^{2} \mathrm{~g}^{-1}$ of the MOF HKUST-1 on pulp fibers [21]. Moreover, it is interesting to note that just a $10 \%$ increase in ZIF-8 loading leads to an over $90 \%$ increase in the measured BET surface area. The results presented here show that a higher MOF content is possible when going from a micrometer scale with pulp fibers to a nanometer scale with CNF. It should be noted that composite microspheres with ZIF-8 shells and CNCs surface-layers have been prepared with a surface area of $1240 \mathrm{~m}^{2} \mathrm{~g}^{-1}$ [45].

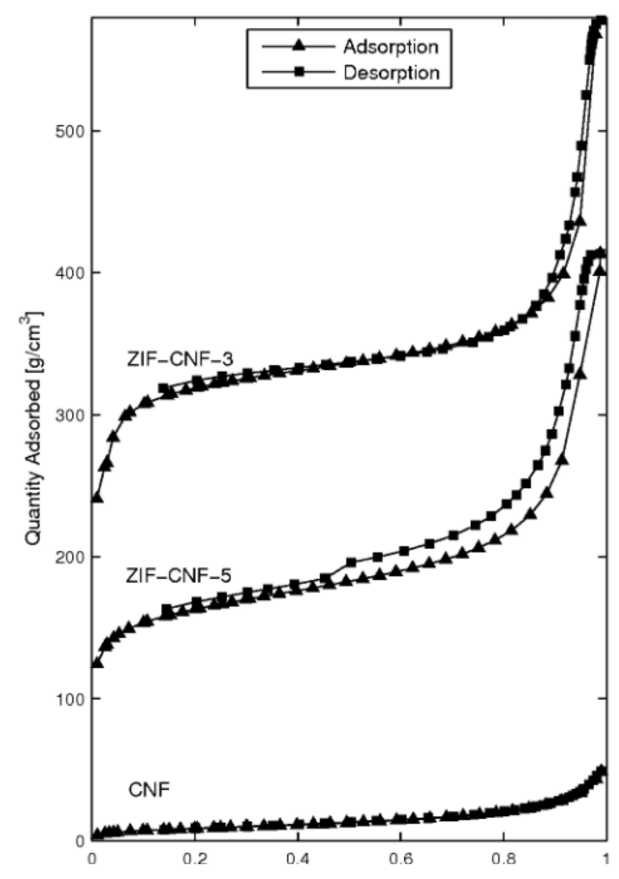

Figure 6. $\mathrm{N}_{2}$ adsorption and desorption isotherms for CNF, ZIF-CNF-5 and ZIF-CNF-3 at $77 \mathrm{~K}$.

In summary, ZIF-8 nanocrystals were synthesized on CNF in aqueous medium and highly porous ZIF-8/CNF hybrid materials could be created by freeze drying. However, optimal strength and loading of ZIF-8 for a potential gas storage or gas separation membrane require further studies. The approach of using a nanocellulose to immobilize ZIF-8 in water is straightforward and has the potential to be easily scaled up. It is also a greener method 
than using dimethylformamide, a common solvent in MOF synthesis. In addition, other MOFs preparable in water can be used to give nanocellulose materials new remarkable properties by this method.

Important questions remaining to answer are how the mechanical properties are affected by the MOF content, and indeed how much MOF can be incorporated and still make a free standing and uniform material (with the same MOF/cellulose environment throughout the bulk).

\section{Materials and Methods}

\subsection{Preparation of TEMPO-Oxidized Cellulose Nanofibrils}

CNF were prepared according to the modified method by Okita et al. [46] $12 \mathrm{~g}$ of softwood kraft pulp was suspended in $1200 \mathrm{~mL}$ water containing $0.19 \mathrm{~g}$ 2,2,6,6-tetramethylpiperidin-1oxyl (TEMPO) and $1.2 \mathrm{~g} \mathrm{NaBr}$. To this solution $25.2 \mathrm{~mL}$ of $2 \mathrm{~mol} \mathrm{dm}{ }^{-3} \mathrm{NaClO}$ was added to start the oxidation. The reaction was performed at room temperature and $\mathrm{pH} 10$ (the $\mathrm{pH}$ was maintained at 10 by addition of $\left.0.5 \mathrm{~mol} \mathrm{dm}{ }^{-3} \mathrm{NaOH}\right)$. When no further decrease in $\mathrm{pH}$ could be observed the reaction was quenched by addition of $10 \mathrm{~mL}$ ethanol. The oxidized pulp was filtered off and thoroughly washed with deionized water. Disintegration to microfibrils was performed with an Ultra-Turrax $\mathrm{T} 45 / \mathrm{N}$ high shear dispersing unit from IKA at $1 \%$ pulp consistency at maximal output for $15 \mathrm{~min}$, cooling to room temperature every $5 \mathrm{~min}$ as the suspension temperature rose during the disintegration.

\subsection{Preparation of Free Standing CNF/ZIF-8 Materials}

The CNF gel ( 3 g or $5 \mathrm{~g}$, (Table 1$)$ ) was added to a stirring solution of 2-methylimidazole (20 mL, $5 \mathrm{M}, 125$ equiv.). The volume was adjusted (35 mL) using deionized water. To this stirring mixture, an aqueous solution of $\mathrm{Zn}\left(\mathrm{NO}_{3}\right)_{2} \cdot 6 \mathrm{H}_{2} \mathrm{O}(5 \mathrm{~mL}, 0.238 \mathrm{~g}, 0.8 \mathrm{mmol}, 1$ equiv. $)$ was added at room temperature. A white precipitate formed and was filtered off. The excess 2-methylimidazole was removed with repeated suspension (deionized water) and centrifugation (4000 rpm, $15 \mathrm{~min}$ ) of the white solid. The suspended precipitate was then frozen with liquid nitrogen dried in a freeze drier (Labconco FreeZone ${ }^{\circledR} 6$ Liter Benchtop 7752030 in conjunction with the FreeZone ${ }^{\circledR}$ Stoppering Tray Dryer 7948030), yielding free standing $\mathrm{CNF} / \mathrm{MOF}$ materials.

\subsection{Characterization}

Micro structural investigations were performed using Scanning Electron Microscopy (SEM) with a LEO Ultra 55 FEG SEM. The SEM was operated at an acceleration voltage of $1.5 \mathrm{kV}$ and all analyzed samples were gold sputtered in a vacuum for $80 \mathrm{~s}$ at $10 \mathrm{~mA}$, yielding approximately a $10 \mathrm{~nm}$ thick gold coating. The surface area of the materials was determined using the Brunauer-Emmett-Teller (BET) multipoint method using nitrogen as the adsorption gas, in a Micromeritics Tristar 3000 at 77 K. Samples were dried under vacuum prior to analysis and the BET surface areas were calculated using the software integrated in the instrumentation. Powder X-ray diffraction patterns were recorded on a Bruker D8 Advance diffractometer equipped with a Lynxeye detector using CuK $\alpha$ radiation $(\lambda=1.5406 \AA)$ at $298 \mathrm{~K}\left(25^{\circ} \mathrm{C}\right)$. Samples were placed on a zero background sample holder and scanned over the $2 \theta$ range of $4^{\circ}$ to $40^{\circ}$ with a step size of $0.01^{\circ}$. X-rays were generated by a current flow of $40 \mathrm{~mA}$ and an accelerating voltage of $30 \mathrm{kV}$. A receiving slit of $0.6 \mathrm{~mm}$ and primary and secondary slits of $2.5 \mathrm{~mm}$ were used. The calculated powder X-ray diffraction patterns were generated by the Mercury 3.3 program from single crystal X-ray data. The program calculated PXRD patterns using the same X-ray source $(\lambda=1.5406 \AA)$ as that used experimentally. FT-IR spectra were recorded on a Perkin Elmer FT-IR Spectrometer Spectrum Two. Samples were scanned over a range of $4000 \mathrm{~cm}^{-1}$ to $450 \mathrm{~cm}^{-1}$. 
Author Contributions: Conceptualization, G.W. and L.Ö.; methodology, J.T.; S.C.Z.; M.H.; O.A.O.; F.M.A.N.; G.W.; L.Ö.; investigation, J.T.; S.C.Z.; O.A.O.; F.M.A.N.; resources, M.H.; G.W.; L.Ö.; writing—original draft preparation, J.T.; writing—review and editing, S.C.Z.; F.M.A.N.; G.W.; L.Ö.; visualization, L.Ö.; supervision, O.A.O.; F.M.A.N.; G.W.; L.Ö.; project administration, G.W. and L.Ö.; funding acquisition, G.W. and L.Ö.; All authors have read and agreed to the published version of the manuscript.

Funding: J.T. and G.W. gratefully acknowledge the Knut and Alice Wallenberg Foundation for financial support through the Wallenberg Wood Science Center. L.Ö. and F.M.A.N. thanks Swedish Research Council. L.Ö. thank the Swedish Research Council for a Swedish Research Links grant, and S.C.Z. the University of Cape Town for financial support as well as the National Research Foundation of South Africa. Any opinion, findings and conclusions or recommendations expressed in this material are those of the authors and do not necessarily reflect the views of the National Research Foundation.

Acknowledgments: The authors thank Jonas Wetterling and Tuve Mattsson at Wallenberg Wood Science Center for their help with $\mathrm{N}_{2}$ adsorption measurements. This work was performed in part at the Chalmers Material Analysis Laboratory, CMAL.

Conflicts of Interest: The authors declare no conflict of interest.

\section{References}

1. Siró, I.; Plackett, D. Microfibrillated cellulose and new nanocomposite materials: A review. Cellulose 2010, 17, 459-494. [CrossRef]

2. Klemm, D.; Kramer, F.; Moritz, S.; Lindström, T.; Ankerfors, M.; Gray, D.; Dorris, A. Nanocelluloses: A New Family of Nature-Based Materials. Angew. Chem. Int. Ed. 2011, 50, 5438-5466. [CrossRef] [PubMed]

3. Isogai, A. Wood nanocelluloses: Fundamentals and applications as new bio-based nanomaterials. J. Wood Sci. 2013, 59, 449-459. [CrossRef]

4. Ferraz, N.; Leschinskaya, A.; Toomadj, F.; Fellström, B.; Strømme, M.; Mihranyan, A. Membrane characterization and solute diffusion in porous composite nanocellulose membranes for hemodialysis. Cellulose 2013, 20, 2959-2970. [CrossRef]

5. Metreveli, G.; Wågberg, L.; Emmoth, E.; Belák, S.; Strømme, M.; Mihranyan, A. A Size-Exclusion Nanocellulose Filter Paper for Virus Removal. Adv. Healthc. Mater. 2014, 3, 1546-1550. [CrossRef]

6. Mautner, A.; Lee, K.-Y.; Tammelin, T.; Mathew, A.P.; Nedoma, A.J.; Li, K.; Bismarck, A. Cellulose nanopapers as tight aqueous ultra-filtration membranes. React. Funct. Polym. 2015, 86, 209-214. [CrossRef]

7. Moore, E.A.; Smart, L.E. Solid State Chemistry: An Introduction, 5th ed.; CRC Press, Inc.: Boca Raton, FL, USA, 2020.

8. Öhrström, L.; Amombo Noa, F.M. Metal-Organic Frameworks; American Chemical Society: Washington, DC, USA, 2021.

9. Yaghi, O.M.; Kalmutzki, M.J.; Diercks, C.S. Introduction to Reticular Chemistry-Metal-Organic Frameworks and Covalent Organic Frameworks; Wiley-VCH: Weinheim, Germany, 2019.

10. Park, J.; Oh, M. Construction of flexible metal-organic framework (MOF) papers through MOF growth on filter paper and their selective dye capture. Nanoscale 2017, 9, 12850-12854. [CrossRef]

11. El Hankari, S.; Bousmina, M.; El Kadib, A. Biopolymer@Metal-Organic Framework Hybrid Materials: A Critical Survey. Prog. Mater. Sci. 2019, 106, 100579. [CrossRef]

12. Mallakpour, S.; Sirous, F.; Hussain, C.M. Metal-organic frameworks/biopolymer nanocomposites: From fundamentals toward recent applications in modern technology. New J. Chem. 2021, 45, 8409-8426. [CrossRef]

13. Riccò, R.; Liang, W.; Li, S.; Gassensmith, J.J.; Caruso, F.; Doonan, C.; Falcaro, P. Metal-Organic Frameworks for Cell and Virus Biology: A Perspective. ACS Nano 2018, 12, 13-23. [CrossRef]

14. Wang, P.-L.; Xie, L.-H.; Joseph, E.A.; Li, J.-R.; Su, X.-O.; Zhou, H.-C. Metal-Organic Frameworks for Food Safety. Chem. Rev. 2019, 119, 10638-10690. [CrossRef] [PubMed]

15. Kirlikovali, K.O.; Chen, Z.; Islamoglu, T.; Hupp, J.T.; Farha, O.K. Zirconium-Based Metal-Organic Frameworks for the Catalytic Hydrolysis of Organophosphorus Nerve Agents. ACS Appl. Mater. Interfaces 2020, 12, 14702-14720. [CrossRef]

16. Zhou, S.Y.; Apostolopoulou-Kalkavoura, V.; da Costa, M.V.T.; Bergstrom, L.; Stromme, M.; Xu, C. Elastic Aerogels of Cellulose Nanofibers@Metal-Organic Frameworks for Thermal Insulation and Fire Retardancy. Nanomicro Lett. 2020, 12, 1-13. [CrossRef] [PubMed]

17. Zhou, S.Y.; Kong, X.Y.; Zheng, B.; Huo, F.W.; Stromme, M.; Xu, C. Cellulose Nanofiber @ Conductive Metal-Organic Frameworks for High-Performance Flexible Supercapacitors. Acs Nano 2019, 13, 9578-9586. [CrossRef]

18. Song, Y.; Seo, J.Y.; Kim, H.; Beak, K.-Y. Structural control of cellulose nanofibrous composite membrane with metal organic framework (ZIF-8) for highly selective removal of cationic dye. Carbohydr. Polym. 2019, 222, 115018. [CrossRef]

19. Seo, J.Y.; Song, Y.; Lee, J.-H.; Kim, H.; Cho, S.; Baek, K.-Y. Robust Nanocellulose/Metal-Organic Framework Aerogel Composites: Superior Performance for Static and Continuous Disposal of Chemical Warfare Agent Simulants. ACS Appl. Mater. Interfaces 2021, 13, 33516-33523. [CrossRef] [PubMed] 
20. Zhou, Q.; Chen, J.; Jin, B.; Chu, S.; Peng, R. Modification of ZIF-8 on bacterial cellulose for an efficient selective capture of U(VI). Cellulose 2021, 28, 5241-5256. [CrossRef]

21. Küsgens, P.; Siegle, S.; Kaskel, S. Crystal Growth of the Metal-Organic Framework Cu3(BTC)2 on the Surface of Pulp Fibers. Adv. Eng. Mater. 2009, 11, 93-95. [CrossRef]

22. da Silva Pinto, M.; Sierra-Avila, C.A.; Hinestroza, J.P. In situ synthesis of a Cu-BTC metal-organic framework (MOF 199) onto cellulosic fibrous substrates: Cotton. Cellulose 2012, 19, 1771-1779. [CrossRef]

23. Rodriguez, H.S.; Hinestroza, J.P.; Ochoa-Puentes, C.; Sierra, C.A.; Soto, C.Y. Antibacterial Activity Against Escherichia coli of Cu-BTC (MOF-199) Metal-Organic Framework Immobilized onto Cellulosic Fibers. J. Appl. Pol. Sci. 2014, 131, 5. [CrossRef]

24. Ozer, R.R.; Hinestroza, J.P. One-step growth of isoreticular luminescent metal-organic frameworks on cotton fibers. RSC Adv. 2015, 5, 15198-15204. [CrossRef]

25. Zhuang, J.-L.; Ar, D.; Yu, X.-J.; Liu, J.-X.; Terfort, A. Patterned Deposition of Metal-Organic Frameworks onto Plastic, Paper, and Textile Substrates by Inkjet Printing of a Precursor Solution. Adv. Mat. 2013, 25, 4631-4635. [CrossRef]

26. Laurila, E.; Thunberg, J.; Argent, S.P.; Champness, N.R.; Zacharias, S.; Westman, G.; Öhrström, L. Enhanced Synthesis of Metal-Organic Frameworks on the Surface of Electrospun Cellulose Nanofibers. Adv. Eng. Mat. 2015, 17, 1282-1286. [CrossRef]

27. Pan, Y.; Liu, Y.; Zeng, G.; Zhao, L.; Lai, Z. Rapid synthesis of zeolitic imidazolate framework-8 (ZIF-8) nanocrystals in an aqueous system. Chem. Commun. 2011, 47, 2071-2073. [CrossRef]

28. Tanaka, S.; Kida, K.; Okita, M.; Ito, Y.; Miyake, Y. Size-controlled Synthesis of Zeolitic Imidazolate Framework-8 (ZIF-8) Crystals in an Aqueous System at Room Temperature. Chem. Lett. 2012, 41, 1337-1339. [CrossRef]

29. Kida, K.; Okita, M.; Fujita, K.; Tanaka, S.; Miyake, Y. Formation of high crystalline ZIF-8 in an aqueous solution. CrystEngComm 2013, 15, 1794-1801. [CrossRef]

30. Zhou, S.Y.; Stromme, M.; Xu, C. Highly Transparent, Flexible, and Mechanically Strong Nanopapers of Cellulose Nanofibers @Metal-Organic Frameworks. Chem. Eur. J. 2019, 25, 3515-3520. [CrossRef] [PubMed]

31. Liang, K.; Wang, R.; Boutter, M.; Doherty, C.M.; Mulet, X.; Richardson, J.J. Biomimetic mineralization of metal-organic frameworks around polysaccharides. Chem. Comm. 2017, 53, 1249-1252. [CrossRef] [PubMed]

32. Raza, A.; Farrukh, S.; Hussain, A.; Khan, I.U.; Noor, T.; Othman, M.H.D.; Yousaf, M.F. Development of high performance amine functionalized zeolitic imidazolate framework (ZIF-8)/cellulose triacetate mixed matrix membranes for $\mathrm{CO}_{2} / \mathrm{CH}_{4}$ separation Int. J. Energy Res. 2020, 44, 7989-7999. [CrossRef]

33. Jia, M.; Zhang, X.-F.; Feng, Y.; Zhou, Y.; Yao, J. In-situ growing ZIF-8 on cellulose nanofibers to form gas separation membrane for $\mathrm{CO}_{2}$ separation. J. Membr. Sci. 2020, 595, 117579. [CrossRef]

34. Pimentel, B.R.; Parulkar, A.; Zhou, E.-k.; Brunelli, N.A.; Lively, R.P. Zeolitic Imidazolate Frameworks: Next-Generation Materials for Energy-Efficient Gas Separations. ChemSusChem 2014, 7, 3202-3240. [CrossRef]

35. Wen, J.; Liu, H.; Zheng, Y.; Wu, Y.; Gao, J. A Novel of PTA/ZIF-8@Cellulose Aerogel Composite Materials for Efficient Photocatalytic Degradation of Organic Dyes in Water. Z. Anorg. Allg. Chem. 2020, 646, 444-450. [CrossRef]

36. Ma, S.; Zhang, M.; Nie, J.; Tan, J.; Song, S.; Luo, Y. Lightweight and porous cellulose-based foams with high loadings of zeolitic imidazolate frameworks-8 for adsorption applications. Carbohydr. Polym. 2019, 208, 328-335. [CrossRef] [PubMed]

37. Bo, S.; Ren, W.; Lei, C.; Xie, Y.; Cai, Y.; Wang, S.; Gao, J.; Ni, Q.; Yao, J. Flexible and porous cellulose aerogels/zeolitic imidazolate framework (ZIF-8) hybrids for adsorption removal of Cr(IV) from water. J. Solid State Chem. 2018, 262, 135-141. [CrossRef]

38. Nabipour, H.; Nie, S.; Wang, X.; Song, L.; Hu, Y. Highly flame retardant zeolitic imidazole framework-8@cellulose composite aerogels as absorption materials for organic pollutants. Cellulose 2020, 27, 2237-2251. [CrossRef]

39. Su, Z.; Zhang, M.; Lu, Z.; Song, S.; Zhao, Y.; Hao, Y. Functionalization of cellulose fiber by in situ growth of zeolitic imidazolate framework-8 (ZIF-8) nanocrystals for preparing a cellulose-based air filter with gas adsorption ability. Cellulose 2018, 25, 1997-2008 [CrossRef]

40. Richardson, J.J.; Tardy, B.L.; Guo, J.; Liang, K.; Rojas, O.J.; Ejima, H. Continuous Metal-Organic Framework Biomineralization on Cellulose Nanocrystals: Extrusion of Functional Composite Filaments. ACS Sustain. Chem. Eng. 2019, 7, 6287-6294. [CrossRef]

41. These Results Were Briefly Discussed in a Recent Ph.D. Thesis: Thunberg, J. Chemical Modification of Electrospun Cellulose Nanofibers. Ph.D. Thesis, Chalmers Tekniska Högskola, Göteborg, Sweden, 2015.

42. Morris, W.; Stevens, C.J.; Taylor, R.E.; Dybowski, C.; Yaghi, O.M.; Garcia-Garibay, M.A. NMR and X-ray Study Revealing the Rigidity of Zeolitic Imidazolate Frameworks. J. Phys. Chem. C 2012, 116, 13307-13312. [CrossRef]

43. Park, K.S.; Ni, Z.; Côté, A.P.; Choi, J.Y.; Huang, R.; Uribe-Romo, F.J.; Chae, H.K.; O'Keeffe, M.; Yaghi, O.M. Exceptional chemical and thermal stability of zeolitic imidazolate frameworks. Proc. Natl. Acad. Sci. USA 2006, 103, 10186. [CrossRef]

44. Schwanninger, M.; Rodrigues, J.C.; Pereira, H.; Hinterstoisser, B. Effects of short-time vibratory ball milling on the shape of FT-IR spectra of wood and cellulose. Vib. Spectrosc. 2004, 36, 23-40. [CrossRef]

45. Ma, J.; Hu, J.; Tang, Y.; Gu, H.; Jiang, M.; Zhang, J. In-situ preparation of hollow cellulose nanocrystals/zeolitic imidazolate framework hybrid microspheres derived from Pickering emulsion. J. Colloid Interface Sci. 2020, 572, 160-169. [CrossRef] [PubMed]

46. Okita, Y.; Saito, T.; Isogai, A. Entire Surface Oxidation of Various Cellulose Microfibrils by TEMPO-Mediated Oxidation. Biomacromolecules 2010, 11, 1696-1700. [CrossRef] [PubMed] 